\title{
O DESENVOLVIMENTO DA COMPETÊNCIA INFORMACIONAL NAS CRIANÇAS A PARTIR DA LITERATURA INFANTIL
}

\author{
Reading children's literature so as to develop Information Literacy
}

\author{
Djuli Machado De Luccal', Clarice Fortkamp Caldin ${ }^{2}$, \\ João Primo Ramirez Righi ${ }^{3}$
}

RESUMO: Objetiva realizar uma reflexão acerca da prática de leitura de literatura infantil enquanto forma de desenvolver a Competência Informacional nas crianças e abordar o papel do bibliotecário e da biblioteca escolar neste contexto. Para tanto, realiza pesquisa exploratória (do ponto de vista dos objetivos) e bibliográfica (do ponto de vista dos procedimentos técnicos). Discorre sobre a Competência Informacional enquanto movimento que estimula o uso crítico e reflexivo da informação. Aborda a primeira fase de desenvolvimento da Competência Informacional, entendida como letramento informacional, que envolve o desenvolvimento de habilidades básicas relacionadas aos suportes informacionais, e que acontece geralmente na infância. Apresenta a leitura de literatura infantil como forma de propiciar o desenvolvimento da Competência Informacional nas crianças, pois apresenta o maravilhoso como forma de entender a realidade. Aponta o bibliotecário e a biblioteca como propulsores do desenvolvimento deste conjunto de habilidades. Ao fim, infere que a função social da literatura infantil consiste no desenvolvimento da Competência Informacional nas crianças. Advoga que a biblioteca deve construir um novo paradigma educacional e o bibliotecário deve acoplar à função de técnico e gestor da informação, a função de educador. Finaliza com sugestões de mudança de comportamento do bibliotecário, a fim de que o mesmo possa participar de forma dinâmica, do letramento informacional, fomentando a leitura de textos literários infantis.

PALAVRAS-CHAVE: Competência Informacional. Letramento Informacional. Literatura Infantil. ABSTRACT: The paper aims at talking about the practice of reading children's literature as a way to develop Information Literacy in children, and discussing the role of the librarian and the school's library in this context. The research is exploratory and bibliographic. Informational Competence is seen as a movement that encourages critical and reflective use of information. Also, the first phase of development of Information Literacy which is understood as information literacy is considered a process. During this stage, the individual develops basic skills related to informational media, usually in childhood. Additionally, the practice of reading children's literature as a way to promote Information Literacy in children is presented. The librarian and the library are pointed out as drivers of development of this set of skills. Furthermore, it states that the social function of children's literature is, in a way, a stimulation of the development of Information Literacy, for the fictional stories as a way of understanding reality. At the end, it infers that the social function of children's literature is the development of Information Literacy in children. It also highlights the library and the librarian as motivators of competence, suggesting that the library should build a new educational paradigm and the librarian must gather the role of manager and information technician with the role of educator. Finally, there are some suggestions of Librarian's change of behavior - from technician to educator, so that s/he can participate in the information literacy in a dynamic manner encouraging the reading of children's literary texts.

KEYWORDS: Information Competence. Information Literacy. Children's literature.

\footnotetext{
${ }^{1}$ Mestranda em Ciência da Informação pela Universidade Federal de Santa Catarina <djuli_mdl@ hotmail.com> ${ }^{2}$ Professora do Programa de Pós Graduação em Ciência da Informação pela Universidade Federal de Santa Catarina <clarice@cin.ufsc.br>

${ }^{3}$ Mestrando em Ciência da Informação pela Universidade Federal de Santa Catarina jprimoramirez@ gmail.com Submetido em: 21/08/2014 - Aceito em: 08/10/2014
} 


\section{INTRODUÇÃ̃o}

Ao longo da trajetória da espécie humana, passamos por diferentes contextos sociais, que exigem algumas competências para acompanhar as inevitáveis mudanças de paradigmas.

Desde meados do século XX vivemos em uma era denominada sociedade da informação, caracterizada, segundo Takahashi (2000, p. 7) como um período em que "a informação flui em quantidades inimagináveis", exigindo dos cidadãos capacidades relacionadas ao uso adequado dos recursos informacionais disponíveis, bem como a apropriação da informação nos diversos contextos.

De acordo com Chauí (2003, p. 131) cidadão é “o indivíduo situado no tecido das relações sociais como portador de direitos e deveres definidos na esfera pública [...]”. Assim, entendemos que, para que sejamos denominados de tal maneira, devemos conhecer as leis, defendermos os interesses do grupo social e termos consciência do que podemos e devemos fazer na esfera pública.

Nesse sentido, para que desfrutemos de qualidade de vida e sejamos efetivamente cidadãos, somos chamados a desenvolver habilidades que permitam o uso consciente, criativo e benéfico da informação (VITORINO; PIANTOLA, 2011). Essa utilização crítica e reflexiva da informação é denominada Competência Informacional.

O desenvolvimento da Competência Informacional envolve diferentes fases, que costumam acompanhar a evolução cognitiva de cada indivíduo. Inicialmente, acontece o processo de letramento informacional ou alfabetização informacional: esta envolve os primeiros contatos do indivíduo com o universo informacional. A fase de desenvolvimento de habilidades informacionais - que também constitui o processo da Competência Informacional - geralmente é desenvolvida após o letramento informacional: nesse processo, o indivíduo geralmente apreende os conteúdos relacionados aos padrões de letramento e aplica-os para resolver problemas. Dessa forma, os conceitos que antes estavam no plano ideológico, passam a se consolidar e tornar aplicáveis. Assim, a Competência Informacional acontece na medida em que o conhecimento - em princípio idealizado e depois aplicado - passa a ser objeto de resolução de problemas: o saber fazer.

A primeira fase de desenvolvimento da Competência Informacional, que apresentamos no parágrafo anterior como letramento informacional ou alfabetização informacional, caracteriza-se pelo período em que o indivíduo se familiariza com o signo, desenvolve habilidades relacionadas aos suportes de informação, aprende sobre organização de livros, 
entre outras habilidades básicas relacionadas com fontes e suportes informacionais (GASQUE, 2012). Esse processo é geralmente desenvolvido na idade escolar, e, portanto, envolve atividades informacionais direcionadas ao público infantil ou infanto-juvenil; é importante para o desenvolvimento da Competência Informacional, pois nessa fase os indivíduos desenvolvem habilidades e comportamentos que vão acompanhá-lo durante toda a vida, como, por exemplo, a habilidade com computadores e a prática de leitura.

A leitura é um fator que influencia no desenvolvimento do letramento informacional e, por conseguinte, da Competência Informacional. Alguns autores (CAMPELLO, 2003; DUDZIAK, 2008) mencionam a leitura como principal elemento para o desenvolvimento tanto das habilidades como dos comportamentos necessários ao convívio social, pelo fato de estimularem o pensamento crítico e a autonomia na utilização da informação.

Destaca-se, no presente, a leitura da literatura infantil, e cabe aqui um aparte: muito embora seja controversa a definição de literatura infantil, os teóricos estão de acordo em um ponto: ela é um ramo da literatura.

Se literatura é considerada um discurso ficcional que privilegia o belo, o estranhamento da linguagem, o uso de metáforas (enfim, arte), a literatura infantil, como um ramo desta, deve ser entendida como arte e não como apelo pedagógico. Como arte, o discurso literário para crianças apresenta, em linguagem metafórica, situações verossímeis em que as personagens ensejam à reflexão e à comparação com a realidade cotidiana. Esse, então, é o grande mérito da literatura infantil: mesclar o maravilhoso com o real, de forma a produzir relações de sentido e entendimento do mundo (CALDIN, 2010).

Como tal, deve distanciar-se do didatismo, pois a arte emociona, desperta a imaginação, aperfeiçoa a inteligência e aprimora a sensibilidade (COUTINHO, 2004).

Assim, literatura infantil pode ser considerada como o principal gênero de leitura para crianças, e possui algumas particularidades para a Competência Informacional, como o impulso à imaginação (VITORINO; PIANTOLA, 2011) - que auxilia no desenvolvimento da capacidade cognitiva - e a consonância com a realidade (GREGORIN FILHO, 2011) - que estimula a capacidade de resolução de problemas, neste caso, de ordem informacional.

Cabe lembrar que a escola às vezes não dá o devido destaque à leitura literária. Mediada por professores e bibliotecários, muitos textos são apresentados como complemento didático, servindo apenas como exercícios gramaticais ou de outra natureza educativa. Acresce o fato de que nem sempre à criança é concedido o direito de escolha - muitas vezes a leitura é impingida como obrigação e não como prazer - o que não condiz com o efeito \begin{tabular}{|l|l|l|l|l|l|l|}
\hline (c) Rev. digit. bibliotecon. cienc. inf. & Campinas, SP & v.13 & n.1 & p.192-206 & jan/abr. 2015 & ISSN 1678-765X \\
\hline
\end{tabular} 
estético que a obra deve exercer sobre o leitor. Muito embora se admita o caráter educativo da literatura infantil, tais textos literários infantis não devem obliterar o lúdico, pois, valendo-se das palavras de Meireles (1984, p. 29), deveria ser classificado como literatura infantil o que as crianças "leem com utilidade e prazer".

Nesse artigo pretendemos realizar uma reflexão sobre a prática da leitura de literatura infantil como forma de desenvolver a Competência Informacional nas crianças, conquanto o ato da leitura da literatura infantil não perca sua potência encantatória. No contexto da literatura infantil e da Competência Informacional, inserimos o bibliotecário e a biblioteca escolar na discussão, pois acreditamos que possuem importante função para o desenvolvimento das habilidades necessárias à Competência informacional.

Explicitamos que a pesquisa, do ponto de vista dos objetivos, configura-se como exploratória, e, do ponto de vista dos procedimentos teóricos, como bibliográfica.

\section{COMPETÊNCIA INFORMACIONAL: UM ENFOQUE PARA DESENVOLVIMENTO NAS CRIANÇAS}

Um ambiente diferente, mutante, problemático e interconectado. Assim Campelo (2003) caracteriza o paradigma atual: a sociedade da informação. Caracterizado por um espaço de sobrecarga informacional, nesse novo contexto o conhecimento é a peça chave para o desenvolvimento de indivíduos e nações. Aos inseridos nesse ambiente, é requerido “competência para transformar a informação em conhecimento" (TAKAHASHI, 2000, p. 7).

Essa competência é denominada Competência Informacional, e surgiu como um movimento inexoravelmente interligado com o paradigma da sociedade da informação (DUDZIAK, 2003) pelo fato de possibilitar que as pessoas utilizem a informação - que está disponível em quantidades e velocidades inimagináveis (TAKAHASHI, 2000) - para o desenvolvimento, a prosperidade e a liberdade (INTERNATIONAL FEDERATION OF LIBRARY..., 2005).

A Competência Informacional contempla um conjunto de habilidades, aqui entendidas como a capacidade que o indivíduo desenvolve para reconhecer quando uma informação é necessária, bem como de localizar, acessar avaliar, utilizar, aplicar e criar essa informação (AMERICAN LIBRARY ASSOCIATION, 1989), de forma consciente, criativa e benéfica (VITORINO; PIANTOLA, 2009). Dessa forma, os cidadãos são motivados rumo a um 
aprendizado contínuo, ao longo da vida, que proporciona o emponderamento pessoal por meio da informação ao permitir que as pessoas sejam críticas e possam criar suas próprias opiniões independentemente (AMERICAN LIBRARY ASSOCIATION, 1989; DUDZIAK, 2008).

Por ser um movimento que estimula a aprendizagem ao longo da vida, a Competência Informacional pode se desenvolver em qualquer idade: infância, adolescência, senescência, porém de forma diferente, ao observar os diferentes estágios de desenvolvimento cognitivo do ser humano.

Na infância - e geralmente na educação infantil - acontece o primeiro contato com a informação, e também os primeiros passos para o desenvolvimento da Competência Informacional, em que o indivíduo desenvolve habilidades relacionadas aos suportes de informação, aprende sobre organização de dicionários e enciclopédias, etc. Neste processo, a Competência Informacional se desenvolve a partir do letramento informacional ou alfabetização informacional (GASQUE; TESCAROLLO, 2010; GASQUE, 2012).

Alguns autores tratam letramento informacional, alfabetização informacional e Competência Informacional como sinônimos (CAREGNATO, 2000; DUDZIAK, 2003). Porém, Gasque (2012) ressalta que, embora sejam processos que se integram e se complementam, não possuem a mesma conotação. A autora reconhece que há uma proximidade conotativa entre "alfabetização informacional" e "letramento informacional", representando estágios similares do desenvolvimento da Competência Informacional (GASQUE, 2012). Quanto ao termo Competência Informacional, sabemos que se trata de um movimento maior, que contempla os demais movimentos, que, nesse contexto, podemos chamar de etapas.

Sem nos atermos a aspectos terminológicos entre letramento e alfabetização - porém adotando para este trabalho o primeiro citado - elegemos a definição de Gasque e Tescarollo (2010, p. 44) que consideram o letramento informacional como "a estruturação sistêmica de um conjunto de competências que integra as ações de localizar, selecionar, acessar, organizar e gerar conhecimento, visando à tomada de decisão e à resolução de problemas".

Dessa feita, consideramos o letramento informacional como o alicerce do desenvolvimento do aprendizado ao longo da vida, uma vez que, ao ser estimulado desde a infância, "favorece o processo de aprender a aprender, e o desenvolvimento de cidadãos competentes e autônomos na busca e no uso da informação" (GASQUE; TESCAROLLO, 2010, p. 45). Assim, a essência do letramento informacional consiste, grosso modo, no engajamento do sujeito no processo de aprendizagem (GASQUE, 2012). Este processo faz \begin{tabular}{l|l|l|l|l|l|l}
\hline (C) Rev. digit. bibliotecon. cienc. inf. & Campinas, SP & v.13 & n.1 & p.192-206 & jan/abr. 2015 & ISSN 1678-765X \\
\hline
\end{tabular} 
com que o aprendente crie novos conhecimentos, que podem desdobrar-se em experiências vividas e guiá-lo para a resolução de futuros problemas, neste caso, de ordem informacional. Destarte, conhecimento é revelado a partir da experiência associada à informação absorvida pelo aprendente.

Percebemos que existe um fator que é determinante no desenvolvimento do letramento informacional para as crianças: a leitura. Esta prática é caracterizada por Bortolin (2010) como um processo de construção de conhecimento e de realidade do mundo vivido. Silva (1984 apud BORTOLIN, 2010) declara que, à medida que o cidadão se apodera da leitura, ele tem maior autonomia e segurança para tomar as suas próprias decisões, ou para não tomá-las. Essas são as “decisões fundamentadas no conhecimento" que Takahashi (2000, p. 45) admite serem tão importantes na sociedade atual e que o letramento informacional proporciona.

Como, nas crianças, a prática da leitura se dá, em sua grande maioria, por meio da literatura infantil, é por meio do lúdico, do maravilhoso, que elas se inserem no universo informacional, uma vez que "linguagem e realidade se prendem dinamicamente" (FREIRE, 1989, p. 9).

\section{LITERATURA INFANTIL: ASPECTOS GERAIS}

Quando pensamos na palavra literatura de um modo geral, o primeiro sentido que nos invoca é arte. Bem como no nosso imaginário, na comunidade científica a literatura é considerada uma arte verbal, não importando se as palavras são escritas ou faladas (DANZIGER, 1974).

Souza (1999, p. 40-41, grifo do autor) esclarece que:

Com relação á palavra literatura, podemos considerar dois significados históricos básicos: $1^{\circ}$ ) até o século XVIII, a palavra mantém o sentido primitivo de sua origem latina - literatura - significando conhecimento relativo às técnicas de escrever e ler, cultura do homem letrado, instrução; $2^{\circ}$ ) da segunda metade do século XVIII em diante, o vocábulo passa a significar produto da atividade do homem de letras, conjunto de obras escritas, estabelecendo-se, assim, a base de suas diversas acepções modernas.

O autor faz a distinção entre literatura lato sensu e literatura stricto sensu, explicitando que o objeto a teoria da literatura é a segunda. Literatura, no sentido estrito, engloba manifestações em linguagem metrificada e não metrificada desde que "em tais manifestações 
se reconheçam propriedades ditas artísticas e/ou ficcionais, por oposição às demais obras escritas - científicas ou técnicas - destituídas de tais propriedades" (SOUZA, 1999, p. 43).

E, de acordo com Samuel (2007, p. 7), "o literário consta de um certo texto que possui a literariedade, constituído pelas metáforas, metonímias, sonoridades, ritmos, narratividade, descrição, personagens, símbolos, ambiguidades e alegorias, os mitos e outras propriedades". Assim, o texto literário, por meio da narrativa, da poesia, do drama, é um texto bem diferente do científico, pois enquanto este último preocupa-se com a exatidão, o primeiro se preocupa apenas com o verossímil, que é apresentado de forma dúbia, posto que bela.

Caldin (2010) destaca as características do objeto literário como sendo: a função estética, a ficção, a colocação em primeiro plano da linguagem, a intemporalidade, a universalidade, o engajamento, a linguagem falante, as propriedades específicas da obra (literariedade) e o efeito estético que a obra exerce sobre o leitor.

Então, literatura tem função estética, vale-se de metáforas, não perde a atualidade, é retomada, expressividade e um desvio da linguagem trivial para a poética, mas também é funcional, ou seja, tem um público a que se destina e produz efeito sobre ele. Em se tratando da literatura infantil, o público é a criança.

$\mathrm{Na}$ literatura infantil, com o maravilhoso ${ }^{4}$, o inimaginável, a dimensão estética se transborda, dando mais espaço à criatividade. Coelho (2000) acredita que enquanto arte e fenômeno da criatividade, a literatura infantil representa o mundo, o homem, a vida, através da palavra, pois funde os sonhos e a vida prática, o imaginário e o real, os ideais e sua possível/impossível realização; assim, une a realidade com a fantasia.

Percebemos que a literatura infantil permite que a criança compreenda (e discuta) os dogmas impostos pela sociedade. A indeterminação das situações transforma-as em universais e atemporais e os fenômenos, conquanto não sigam as leis naturais, são válidos no imaginário infantil, pois seguem suas próprias leis - as da ficcionalidade. É justamente o jogo da fantasia que cativa a criança, que a envolve no texto, que, brincando, a faz pensar, criticar.

Para Caldin (2003, p. 51), "as historias contemporâneas, ao apresentarem as dúvidas da criança em relação ao mundo em que vive, abrem espaço para o questionamento e a reflexão" ao passo que os contos clássicos envolvem "o aguçar de sua sensibilidade artística e o equilibrar o sonho com o real".

${ }^{4}$ Oliveira (2005) explica que o maravilhoso significa todas aquelas situações que ocorrem fora do nosso entendimento da dicotomia espaço/tempo ou realizada em local vago ou indeterminado na terra. A autora também destaca que tais fenômenos não obedecem às leis naturais que regem o planeta. 
Pode-se mesmo dizer que tanto as histórias contemporâneas como as clássicas apresentam os problemas e conflitos comuns a todo ser humano, em qualquer época de sua vida ou da história da humanidade: fome, medo, insegurança frente ao desconhecido, inveja; mas mostram também o valor do amor, da amizade, da coragem e da bondade. Os contos infantis, pela especificidade do público, reforçam sempre as virtudes, que (pretende a visão adultocêntrica), sirvam de modelo comportamental para as crianças. Entretanto, não deixam de mostrar o outro lado da moeda: os defeitos (tidos como indesejáveis), mas necessários na narrativa para fazer a dicotomia bom/mau que caracteriza o enredo (e a vida de todos nós) (CALDIN, 2010).

Gregorin Filho (2011, p. 9) também menciona o caráter realista da literatura infantil:

\begin{abstract}
o que se percebe é a existência de uma literatura que pode ser chamada de infantil apenas no nível de manifestação textual, isto é, no nível do texto em que o leitor entra em contato com as personagens, tempo, espaço, entre outros elementos textuais; percebe-se também que os temas não diferem dos temas presentes em outros tipos de texto que circulam na sociedade, como a literatura para adultos e o texto jornalístico, por exemplo. Isso também parece bastante claro, pois os valores discutidos na literatura para crianças são valores humanos, construídos através da longa caminhada humana pela história, e não valores que circulam apenas no universo infantil das sociedades contemporâneas.
\end{abstract}

Pelo fato de a literatura infantil despertar a criança para os valores e ideais, Palo e Oliveira (2006, p. 9) destacam que a literatura infantil "está atrelada à função utilitáriopedagógica que a faz ser mais pedagogia do que literatura". Essas autoras condenam o uso que a escola faz do texto literário priorizando o didatismo e esquecendo seu valor estético; condenam, também, a utilização abusiva das temáticas sociais desse tipo de produção, pois entendem que obliteram seu caráter poético.

Caldin (2003, p. 51), discorre sobre o papel social da literatura:

\begin{abstract}
pode-se dizer que o movimento da literatura infantil contemporânea, ao oferecer uma nova concepção de texto escrito aberto a múltiplas leituras, transforma a literatura para crianças em suporte para experimentação do mundo. Dessa maneira, as histórias contemporâneas, ao apresentarem as dúvidas da criança em relação ao mundo em que vive, abrem espaço para o questionamento e a reflexão, provenientes da leitura.
\end{abstract}

Ao fazer uma analogia com a função social da literatura em geral, essa autora acredita que a literatura infantil cumpre sua função social na medida em que auxilia a criança a compreender - e assim, emancipar-se - dos dogmas que a sociedade lhe impõe. A autora 
afirma que desvincular-se destes dogmas “é possível pela reflexão crítica e pelo questionamento proporcionados pela leitura" (CALDIN, 2003, p. 51).

Admitimos que a literatura infantil tem papel pedagógico e social (sempre embutidos na efabulação), mas consideramos importante o discurso literário se preocupar com a sensibilidade da criança e ter apelo estético.

Entendemos também que a literatura e a leitura auxiliam o cidadão a entender a realidade que o cerca, a acompanhar as mudanças da sociedade, e a ter autonomia e liberdade. Assim, estabelecemos a relação entre Competência Informacional e literatura infantil: esta última como um importante meio de estimular na criança o desenvolvimento da primeira.

\section{O PAPEL DO BIBLIOTECÁRIO ESCOLAR NO DESENVOLVIMENTO DA COMPETÊNCIA INFORMACIONAL NAS CRIANÇAS}

Vamos mais além: considerando que a Competência Informacional possui a missão de formar cidadãos reflexivos, críticos e autônomos e a literatura infantil, a função social de, pelas histórias, apresentarem as dúvidas da criança em relação ao mundo em que vive, abrir espaço para o questionamento e a reflexão provenientes da leitura (CALDIN, 2003), é evidente que, ao relacionar ambos, estamos nos referindo ao mesmo movimento. Dessa forma, acreditamos que, quando os autores mencionam a função social da literatura infantil, eles estão, concomitantemente, se referindo ao desenvolvimento da Competência Informacional nas crianças.

O ambiente da biblioteca escolar mostra-se propício para o desenvolvimento da Competência Informacional nas crianças. A esse respeito, o Manifesto da IFLA para bibliotecas escolares declara que:

\footnotetext{
A biblioteca escolar (BE) propicia informação e ideias fundamentais para seu funcionamento bem sucedido na atual sociedade, baseada na informação e no conhecimento. A BE habilita os estudantes para a aprendizagem ao longo da vida e desenvolve a imaginação, preparando-os para viver como cidadãos responsáveis (INTERNATIONAL FEDERATION OF LIBRARY ASSOCIATIONS AND INSTITUTIONS, 2000, p. 1).
}

Caldin (2003) afirma que este ambiente é, por excelência, o local para apresentar a leitura como uma atividade natural e prazerosa, posto que, para muitas crianças, configura-se 
como a única oportunidade de ter acesso aos livros que não são didáticos. Idealmente, a biblioteca escolar tem o papel de oferecer ao aluno a educação que ensine a aprender a aprender e auxiliar no desenvolvimento de habilidades para buscar e usar informação (CAMPELLO, 2003). Porém, nos deparamos com a falta de iniciativas neste âmbito, o que configura, segundo Gasque e Tescarollo (2010, p. 52), num desafio para a implementação do letramento informacional na educação básica, uma vez que "elas [as bibliotecas] têm sido, via de regra, ignoradas ou negligenciadas e, quando existentes, consideradas meros apêndices do sistema educacional".

Nesse período, em que o movimento da Competência Informacional toma dimensões cada vez maiores, Campello (2003) afirma ser este o momento de se ampliar a função pedagógica da biblioteca: ou, em outras palavras, construir um novo paradigma educacional, fazendo-se assim reconhecer a importância deste ambiente para o aprendizado.

No ambiente da biblioteca escolar o bibliotecário pode exercer papel de educador para o desenvolvimento da Competência Informacional. Conforme Aguiar (2006, p. 259)

\begin{abstract}
Ao ressaltarmos o caráter dinâmico da biblioteca na escola, avulta a figura do bibliotecário. A ele são atribuídas funções específicas, uma vez que a biblioteca escolar é um espaço diferenciado da sala de aula, com características próprias. Para que ela cumpra seu papel, não bastam acervo e espaço físico: é necessário, antes de tudo, o trabalho do bibliotecário como animador cultural.
\end{abstract}

Como animador cultural, é seu mister, entre outros, ter uma participação ativa no desenvolvimento da Competência Informacional nas crianças. Campello (2003) afirma categoricamente que este profissional é a figura central no discurso da Competência Informacional. Num plano ideal, este profissional seria o educador para a Competência Informacional, aquele que participa ativamente do planejamento curricular e está disposto a abandonar a postura de isolamento, concentrada apenas nas atividades da biblioteca e, ao mesmo tempo, privilegia estratégias de aprendizagem condizentes com as teorias educacionais recentes (CAMPELLO, 2003). Porém, Ross Todd (apud CAMPELLO, 2003) declara que a função pedagógica se mostra para o bibliotecário ao mesmo tempo complexa e desafiadora, uma vez que a dimensão tecnicista predomina dentre as competências deste profissional.

Também é interessante nos atentarmos à prática da leitura. Já citamos anteriormente que a leitura é uma forma determinante de desenvolvimento do letramento informacional, porém, Silva (2009) destaca que apenas a leitura crítica pode nos ajudar a absorver a realidade 
e assim desenvolvermos o letramento informacional. $\mathrm{O}$ autor caracteriza a leitura crítica pela capacidade de:

raciocinar sobre os referenciais de realidade desse texto, examinando cuidadosa e criteriosamente os seus fundamentos. Trata-se de um trabalho que exige lentes diferentes das habituais, além de retinas sensibilizadas e dirigidas para a compreensão profunda e abrangente dos fatos sociais. (SILVA, 2009, p. 27)

Podemos nos perguntar: mas nas histórias infantis, com a presença da fantasia, do maravilhoso, seria possível uma criança ler criticamente? Vitorino e Piantola (2011, p. 103) afirmam que a estética - principal atributo da literatura - consiste em unir imaginação com realidade usando o senso crítico, pois toda informação, literária ou não, transmite-se aos indivíduos a partir de referenciais do mundo exterior, com base em dados empíricos, verificáveis, objetivos, e também do mundo interior, por meio da intuição, da sensibilidade, da imaginação e da reflexão pessoal.

Dessa forma, ao desenvolver a Competência Informacional, a criança usa o senso crítico para avaliar a informação, e a imaginação - e pode perfeitamente partir do maravilhoso para experimentar essa informação.

\section{CONSIDERAÇÕES FINAIS}

$\mathrm{Na}$ sociedade da informação a Competência Informacional se mostra como a disciplina básica. Nesse ambiente - considerado potencialmente desafiador em termos informacionais - somos chamados a desenvolver a Competência Informacional e o aprendizado ao longo da vida desde o primeiro contato com a informação, para que sejamos efetivamente cidadãos e possamos desfrutar de qualidade de vida.

Denominamos letramento informacional o processo que envolve as primeiras habilidades relacionadas à informação, a partir do qual nos familiarizamos com o universo informacional e aprendemos algumas habilidades básicas com relação aos suportes e conteúdos informacionais. Nessa fase, a leitura se mostra como elemento substancial.

Por se tratar de um processo que geralmente é desenvolvido nas crianças, apresentamos, neste artigo, a prática de leitura da literatura infantil como um meio de desenvolver o letramento informacional nos indivíduos.

A literatura infantil se mostra, a partir do maravilhoso, como uma fonte de realidade, já que os temas que encontramos nas obras maravilhosas, os clássicos, em geral não diferem 
dos temas presentes em outros tipos de texto que circulam na sociedade. E os textos literários infantis contemporâneos também cumprem um papel social, pois mostram as vivências atuais e apresentam estratégias de enfrentamento dos problemas pessoais e coletivos.

Dessa forma, inferimos que a função social da literatura infantil consiste no desenvolvimento da Competência Informacional nas crianças, na medida em que estimula a refletir sobre as informações, questioná-las e usá-las na resolução de problemas.

Destacamos, como propulsores dessa competência, a biblioteca e o bibliotecário. Assim, consideramos que a biblioteca deve construir um novo paradigma educacional e o bibliotecário deve acoplar à função de técnico e gestor da informação, a função de educador.

$\mathrm{Na}$ dinâmica das relações entre biblioteca e criança, o bibliotecário ocupa um lugar privilegiado que não deve desprezar: ao fomentar a leitura de textos literários infantis, esse profissional deve ter consciência de que participa no letramento informacional e que contribui para que a Competência Informacional possa ser uma realidade no ambiente da sociedade da informação.

\section{REFERÊNCIAS}

AGUIAR, V. T. O caminho dos livros: da biblioteca à comunidade. In: AGUIAR, V. T.; MARTHA, A. Á. P. (Org.). Territórios da leitura: da literatura aos leitores. São Paulo: Cultura Acadêmica; Assis: ANEP, 2006. p. 255-267.

\section{AMERICAN LIBRARY ASSOCIATION. Presidential Committee on Information}

Literacy: final report. Washington, 1989. Disponível em:

<http://www.ala.org/acrl/publications/whitepapers/presidential>. Acesso em: 16 dez. 2013.

BORTOLIN, S. Mediação oral da literatura: a voz dos bibliotecários lendo ou narrando. 2010. 233f. Tese (Doutorado em Ciência da Informação) - Universidade Júlio de Mesquita Filho, Faculdade de Filosofia e Ciências, Marília, 2010.

CALDIN, C. F. A função social da leitura da literatura infantil. Encontros Bibli, Florianópolis, n. 15, jan./jul. 2003. Disponível em: <http://estudiosterritoriales.org/articulo.oa?id=14701505> . Acesso em: 27 jan. 2014. 
CALDIN,_C. F. Biblioterapia: um cuidado com o ser. São Paulo: Porto de Ideias, 2010.

CAMPELLO, B. O movimento da competência informacional: uma perspectiva para o letramento informacional. Ciência da Informação, Brasília, v. 32, n. 3, p. 28-37, set./dez. 2003.

CAREGNATO, S. E. O desenvolvimento de habilidades informacionais: o papel das bibliotecas universitárias no contexto da informação digital em rede. Rev. de Bibliotecon. \& Comum. Porto Alegre,v. 8, p. 47-55, 2000. Disponível em: http://eprints.rclis.org/bitstream/10760/11663/1/artigoRBC.pdf Acesso em: 02 dez. 2013.

CHAUÍ, M. Convite à filosofia. 13. ed. São Paulo: Ática, 2003.

COELHO, N. N. Literatura infantil: teoria, análise, didática. São Paulo: Moderna, 2000.

COUTINHO, A. (Dir.). A literatura no Brasil. 7. ed. São Paulo: Global, 2004. v.6.

DANZIGER, M. K.; JOHNSON W. S. Introdução ao estudo crítico da literatura. São Paulo: Cultrix, 1974.

DUDZIAK, E. A. Information Literacy: princípios, filosofia e prática. Ciência da Informação, Brasília, v. 32, n. 1, p. 23-35, jan./abr. 2003.

DUDZIAK, E. A. Os faróis da sociedade da informação: uma análise crítica sobre a situação da competência em informação no Brasil. Informação e Sociedade: estudos, João Pessoa, v. 18, n. 2, p. 41-53, maio/ago. 2008.

FREIRE, P. A importância do ato de ler: em três artigos que se completam. São Paulo: Autores associados: Cortez, 1989. (Coleção polêmicas do nosso tempo, 4). 
GASQUE, K. C. G. Letramento informacional: pesquisa, reflexão e aprendizagem. Brasília: Editora FCI/UnB, 2012. Disponível em: <

http://leunb.bce.unb.br/bitstream/handle/123456789/22/Letramento_Informacional.pdf?seque nce $=3>$. Acesso em: 18 jan. 2014.

GASQUE, K. C. G. D.; TESCAROLLO, R. Desafios para implementar o letramento informacional na educação básica. Educação em revista, Belo Horizonte, v. 26, n. 01, p. 4146, abr. 2010.

GREGORIN FILHO, J. N. Literatura Infantil: múltiplas linguagens na formação de leitores. São Paulo: Melhoramentos, 2011. 128 p. Disponível em: <http://books.google.com.br/books?id=6XTJrrEcyEAC\&pg=PT6\&hl=ptBR\&source=gbs_toc_r\&cad=4\#v=onepage \&q\&f=false>. Acesso em: 26 jan. 2013.

\section{INTERNATIONAL FEDERATION OF LIBRARY ASSOCIATIONS AND}

INSTITUTIONS. Manifesto IFLA/UNESCO para bibliotecas escolares. Tradução de Neusa Dias de Macedo. 2000. Disponível em: <http://archive.ifla.org/VII/s11/pubs/portuguese-brazil.pdf >. Acesso em: 28 jan. 2014.

\section{INTERNATIONAL FEDERATION OF LIBRARY ASSOCIATIONS AND}

INSTITUTIONS. Declaração de Alexandria sobre competência informacional e aprendizado ao longo da vida. In: NATIONAL FÓRUM ON INFORMATION LITERACY, 2005. Disponível em: 〈www.ifla.org/III/wsis/BeaconInfSoc-pt.html $>$. Acesso em 26 jan. 2013.

MEIRELES, C. Problemas da literatura infantil. 3. ed. Rio de Janeiro: Nova Fronteira, 1984.

OLIVEIRA, C. M. A importância do maravilhoso na literatura infantil. 2005. Disponível em: < http://www.graudez.com.br/litinf/marav.htm> Acesso em: 29 jan. 2014.

PALO, M. J.; OLIVEIRA, M. R. D. Literatura infantil: voz de criança. 3. ed. São Paulo: Ática, 2006. Disponível em: < http://www.visionvox.com.br/biblioteca/m/Maria-Jose-Palo-\&- 
Maria-Rosa-D.-Oliveira-Literatura-Infantil,-Voz-de-Crian\%C3\%A7a-doc-rev-.pdf >. Acesso em: 28 jan. 2014.

TODD, R. Transitions for preferred futures of school libraries. In: THE 2001 IALS CONFERENCE, 2001, Auckland. Keynote paper. Seattle : International Association of School Librarianship, 2001. Disponível em : <http://www.ials-slo.org/virtualpaper2001.html >

SAMUEL, R. Novo manual de teoria literária. 4. ed. rev.e ampl. Petrópolis: Vozes, 2007.

SILVA, Ezequiel Theodoro da. A ato de ler: fundamentos psicológicos para uma ... 3.ed. São Paulo: Cortez, 1984. Coleção educação contemporânea.

SILVA, E. T. Criticidade e leitura: Ensaios. 2. ed. São Paulo: Global, 2009.

SOUZA, R. A. Teoria da literatura. 7. ed. São Paulo: Ática, 1999.

TAKAHASHI, T. Sociedade da informação no Brasil: livro verde. Brasília: Ministério da Ciência e Tecnologia, 2000.

VITORINO, E. V.; PIANTOLA; D. Competência Informacional - bases históricas e conceituais: construindo significados. Ciência da Informação, Brasília, v. 38, n.3, p. 130141, set./dez., 2009.

VITORINO, E. V.; PIANTOLA, D. Dimensões da Competência Informacional. Ciência da Informação, Brasília, v. 40 n. 1, p. 99-110, jan./abr., 2011.

\section{Como citar este artigo:}

LUCCA, Djuli Machado De; CALDIN, Clarice Fortkamp; RIGHI, João Primo Ramirez. O desenvolvimento da competência informacional nas crianças a partir da literatura infantil. Rev. digit. bibliotecon. cienc. inf., Campinas, SP, v.13, n.1, p.192-206, jan/abr. 2015. ISSN 1678-765X. Disponivel em: <http://www.sbu.unicamp.br/seer/ojs/index.php/rbci>. Acesso em: 31 Jan. 2015. 